\title{
Relationship of theoretical patch climatology to polar cap patch observations
}

\author{
M. D. Bowline, J. J. Sojka, and R. W. Schunk \\ Center for Atmospheric and Space Sciences, Utah State University, Logan
}

\begin{abstract}
During a southward orientation of the interplanetary magnetic field (IMF), patches are often observed moving antisunward across the polar cap. In saying "patches" we refer to structures in which the $F$ region electron densities are enhanced relative to lower background levels; we do not in this paper consider patches which are observed optically (see J. J. Sojka et al., Ambiguity in identificiation of polar cap $F$ region patches, submitted to the Journal of Atmospheric and Terrestrial Physics, 1995). The patches can be modeled by a process which involves the "chopping up" of the tongue of ionization (TOI) [Sojka et al., 1993a]. Various mechanisms for chopping the TOI have been suggested; our preferred method is to introduce temporal changes in the convection electric field pattern. In any case the present study is quite independent of any particular mechanism, so long as the TOI is considered to be the source of the patches. In this study we have used the Utah State University Time-Dependent Ionospheric Model (TDIM) to model the TOI for various IMF $B_{y}$ orientations. In our simulations the location of the TOI in the polar cap is mainly determined by the IMF $B_{y}$ component, and hence the patch locations are also expected to be $B_{y}$ dependent. This suggests that a polar ground-based instrument may not see patches even when they are present in the polar ionosphere. This is because the typical field of view of a ground-based instrument, such as an all-sky camera, covers less than $10 \%$ of the polar region. The TDIM simulation results were used to predict the $B_{y}$ dependence of patches that different ground-based sites would observe. Eureka (Canada) at the magnetic pole is predicted not to observe patches for southward IMF conditions if the $B_{y}$ component is strongly negative.

Sondrestrom (Greenland) and NyAlesund (Svalbard), although at similar cusp latitudes, are expected to see quite different diurnal responses to patches. At Sondrestrom, patches are seen at noon in winter; both sites should see them in the premidnight sector. These model predictions are the "groundwork" for detailed patch observation-model comparisons at all three sites.
\end{abstract}

\section{Introduction}

Buchau et al. [1983] have shown that polar $F$ region density structures come in two main forms, that is, patches and sun-aligned arcs. The patches were found to correlate with times of strong geomagnetic activity. Today we also know that the patches form under southward interplanetary magnetic field (IMF) conditions. Weber et al. [1984] showed that the patches were transported into the polar cap rather than formed locally by precipitation. Foster and Doupnik [1984] observed plasma transport into the cusp region, through it, and into the polar cap. This transport of plasma, specifically patches, from the cusp into the

Copyright 1996 by the American Geophysical Union.

Paper number 96RS00236.

0048-6604/96/96RS-00236\$11.00 polar cap was also observed by Weber et al. [1986]. Patches were observed to have a strong diurnal modulation in winter when viewed from Thule in the center of the polar cap [Buchau et al., 1985].

These observations show that the patches convect across the polar cap at the prevailing convection speed. This convection is predominantly antisunward for southward IMF conditions. The convection can be traced backward, through the cusp, into a dayside region equatorward of the auroral ionosphere. Hence the origin of the patches could be equatorward of the cusp region, in the cusp region, or a combination of both. Weber et al. [1984, 1986] had already shown that patches do not originate inside the polar cap. Indeed, Tsunoda [1988] synthesized a descriptive model of large-scale patches by including a combination of mechanisms. First, plasma transport convects high-density, solar-produced plasma from lower latitudes into the cusp. Historically, the feature that develops in association with this transport through the cusp and across the polar cap is referred to as the "tongue of 
ionization" (TOI). Sato [1959] identified this region of enhanced polar cap plasma in maps of ground-based $f_{o} F_{2}$ and proposed that the "tongue" was caused by solarilluminated plasma drifting into the polar cap. Because of the offset between the magnetic and geographic poles, this solar-produced phenomenon has a strong UT modulation, and hence in different longitude sectors its intensity is different. This was modeled by Sojka and Schunk [1982], observed by de la Beaujardiere et al [1985], and is consistent with the patch UT modulation observed by Buchau et al. [1985]. The role of time variations in the convection electric field as the mechanism that chops the TOI into patches has been extensively modeled [Anderson et al., 1988; Lockwood and Carlson, 1992, Bowline et al., 1992, 1993; Sojka et al., 1992, 1993a, b, 1994; Decker et al., 1994] and has been observed by Rodger et al. [1994] and Valladares et al. [1994]. This mechanism has also been shown to be a primary mechanism for boundary blobs (D. N. Anderson et al., Modeling boundary blobs using time varying convection, submitled to Geophysical Research Letters, 1995).

Both observationally and theoretically, the polar cap patch phenomenon is a tantalizing "weather" phenomenon. In the applications community it is also a noticeable bad weather effect. The steep density gradients found at the edges of the patches lead to instabilities and the generation of plasma irregularities at various smallscale sizes. It is these irregularities which lead to severe problems in applications involving radio waves traversing the ionosphere. Finally, it should be noted that most of the present-day research dealing with polar cap patches stems from the National Science Foundation Coupling Energetics and Dynamics of Atmospheric Regions (CEDAR) High-Latitude Plasma Structure (HLPS) workshop held at Peaceful Valley, Colorado, in May 1992. At this meeting, almost all of the mechanisms mentioned in this introduction were presented and discussed.

This study extends the work of Bowline et al. [1993] and Sojka et al. [1993a, 1994] by presenting the UT and seasonal dependence of patches as might be seen via an observer's localized view from a ground station rather than the theoretical "global" presentation made in the earlier two papers. Three stations are considered: Eureka (Canada), Sondrestrom (Greenland), and NyAlesund (Svalbard). These sites have been chosen because of the large amount of HLPS-type campaign data acquired at these locations. The authors are working with the researchers who acquired these data sets and plan to follow up this theoretical study with observation-model studies.

\section{Time-Dependent Ionospheric Model (TDIM)}

The ionospheric model was initially developed as a midlatitude, multi-ion $\left(\mathrm{NO}^{+}, \mathrm{O}_{2}^{+}, \mathrm{N}_{2}^{+}\right.$, and $\left.\mathrm{O}^{+}\right)$model by
Schunk and Walker [1973]. The time-dependent ion continuity and momentum equations were solved as a function of altitude for a corotating plasma flux tube, including diurnal variations and all relevant $E$ and $F$ region processes. This model was extended to include highlatitude effects due to convection electric fields and particle precipitation by Schunk et al. [1975, 1976]. A simplified ion energy equation was also added, which was based on the assumption that local heating and cooling processes dominate (valid below $500 \mathrm{~km}$ ). Flux tubes of plasma were followed as they moved in response to convection electric fields. A further extension of the model to include the minor ions $\mathrm{N}^{+}$and $\mathrm{He}^{+}$, an updated photochemical scheme, and the mass spectrometer incoherent scatter (MSIS) atmospheric model is described by Schunk and Raitt [1980].

The addition of plasma convection and particle precipitation models is described by Sojka et al. [1981a, b]. Schunk and Sojka [1982] extended the ionospheric model to include ion thermal conduction and diffusion thermal heat flow. Also, the electron energy equation was included by Schunk et al. [1986], and consequently, the electron temperature is now rigorously calculated at all altitudes. The theoretical development of the TimeDependent lonospheric Model (TDIM) is described by Schunk [1988], while comparisons with observations are discussed by Sojka [1989].

In addition to the convection input, the TDIM requires several other inputs. The auroral oval parameters, specifically the electron energy flux and average energy, were obtained from the Hardy et al. [1987] model. The geomagnetic activity was set at $K_{p}=3.5$. The MSIS- 86 model was used to represent the neutral atmosphere [Hedin, 1987]. A solar maximum condition was assumed, represented by an $F_{10.7}$ index of 210 . These additional inputs were all kept constant during the TDIM simulations.

\section{Patch-to-Background Ratio}

Our prior patch studies [Sojka et al., 1993a, 1994] showed that the $F$ region polar cap patches were associated with the tongue of ionization, which was the plasma source for the patches. In these studies the chopping of the tongue into patches was due to temporal changes in the convection electric field; these changes in turn were associated with IMF $B_{y}$ variations and electrodynamic changes ongoing in the cusp region, which is the entry point of the patches into the polar cap. Hence by studying the enhancement of the plasma density in the TOI relative to the other plasma in the polar cap, referred to as the background, it is possible to predict the density enhancement of patches as a function of UT, season, solar cycle, etc. In an earlier theoretical study [Bowline et al., 1993] we chose a dawn-dusk strip across the polar cap as the region from which to obtain the TOI density and lowest 
background density. Hence at each UT and season it was possible for the TDIM to predict the ratio of a patch (TOI)to-background density ratio.

Figure 1 shows the result of this analysis carried out for the northern hemisphere (color versions of the figures in this paper, as well as figures from related papers, can be accessed via the Internet at this address: http://sojka.cass.usu.edu/papers/patches/). In the UTseasonal format the model predicts a well-defined pattern, which we refer to as a "bull's-eye". Near winter solstice (days 345-365) a well-defined UT variation is apparent with a minimum ratio at about 0800 UT and a maximum at about 2200 UT. This diurnal (UT) variation changes with season, and by equinox (days $60-80$ and $265-285$ ) the winter phase relationship is almost reversed. Between equinox and summer, relatively low ratios are expected, since the entire polar region is sunlit and the TOI is not a strong density feature.

In our earlier study [Bowline et al., 1993] we showed that this bull's-eye pattern is relatively invariant to changes in IMF $B_{y}$. This was because our ideal dawn-dusk polar cap slice, like a satellite pass, intersected the TOI and the
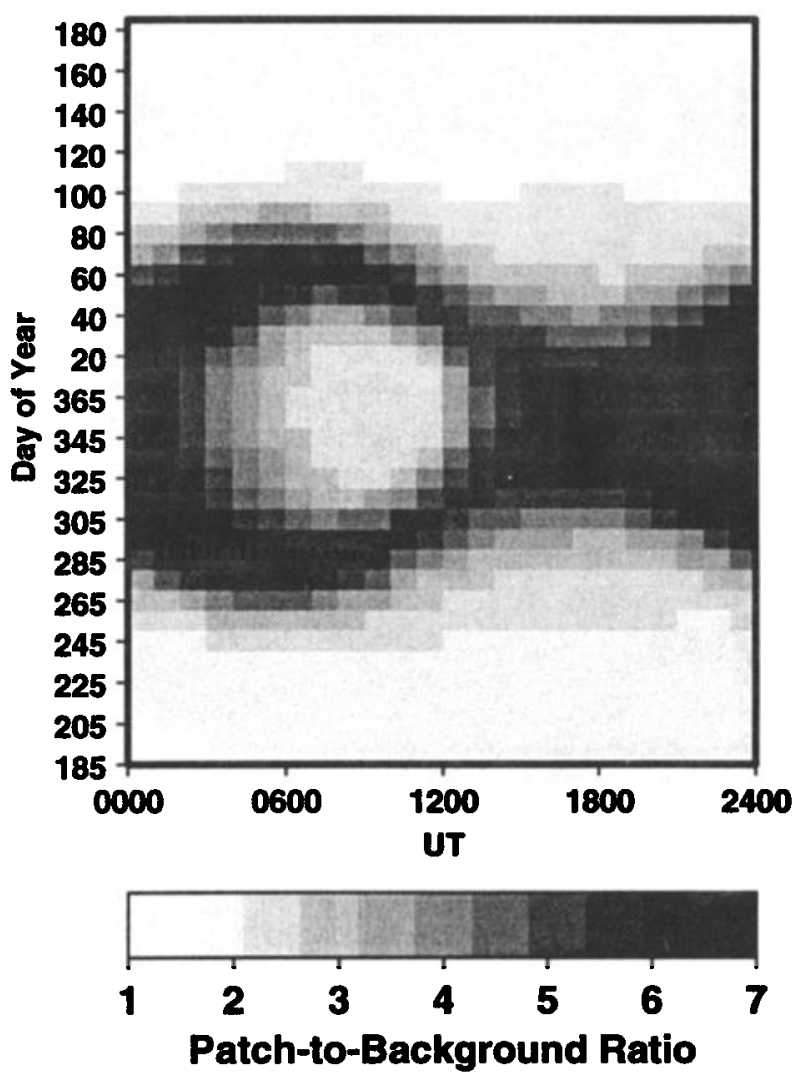

Figure 1. Patch-to-background $N_{m} F_{2}$ ratio as a function of UT and season. The ratio is computed as described in the text. minimum density region for all $B_{y}$ conditions. However, ground-based observers with an all-sky field of view cannot sample this entire slice. A typical field of view of a ground station ranges from $400-$ to $500-\mathrm{km}$ radius. However, the polar cap has a diameter of more than $3000 \mathrm{~km}$. Hence it is unlikely that the global theoretical predictions shown in Figure 1 correspond to what a particular ground station would observe locally.

Figure 2 shows the different locations of the TOI for two extreme IMF $B_{y}$ orientations. The left panel corresponds to $B_{y}$ negative ("DE" convection pattern of Heppner and Maynard [1987]), while the right panel corresponds to $B_{y}$ positive ("BC" convection pattern). In the polar cap noon sector the two TOIs are located more than $1000 \mathrm{~km}$ apart. (This can be estimated by using the latitude scale and roughly assuming that $1 \mathrm{deg}$ corresponds to $100 \mathrm{~km}$.) Given that a typical station's field of view is less than $1000 \mathrm{~km}$ in diameter, this implies that a station located under the $B_{y}$ negative duskside TOI would not see the TOI if the $B_{y}$ were positive and vice versa.

In the following sections we consider several locations for ground-based observations, and then we show how sensitively patch observability is affected by the observer's location and restricted field of view. In each case the station's field of view is represented by a $13 \times 13$ array of pixels; each pixel corresponds to a $70 \times 70 \mathrm{~km}^{2}$ area. At each UT the TDIM follows 169 trajectories (one per pixel) and produces an $N_{m} F_{2}$ snapshot. These snapshots are then analyzed to find the maximum and minimum $N_{m} F_{2}$. The ratio of the maximum to minimum $N_{m} F_{2}$ is used as the local patch-to-background ratio. This ratio is defined quite differently from that used to create Figure 1, but it more realistically simulates an observational capability.

\section{Simulated Eureka (Canada) Observations}

Eureka is an observatory located within $1 \mathrm{deg}$ of the magnetic pole in the northern hemisphere at $80^{\circ} \mathrm{N}$ and $273^{\circ} \mathrm{E}$ in the Northwest Territories on Ellesmere Island in Canada. This observatory has several aeronomy instruments that monitor the polar ionosphere, including a scanning photometer and all-sky camera (D. McEwen, University of Saskatchewan), a low light level all-sky TV system (D. Steele, University of Calgary), and a digital ionosonde Canadian Advanced Digital Ionosonde (CADI) (J. McDougal, University of Western Ontario). In the future we are planning to conduct a joint observation-model study of polar ionospheric patches as a follow-on to this theoretical study. The Eureka location is such that its field of view remains relatively fixed in the magnetic local time frame, nearly centered on the magnetic pole. This field of view, when superimposed on the two IMF $B_{y}$ tongues shown in Figure 2, yields different results. For the $B_{y}$ negative case (left panel) it does not reach the TOI located 
IMF B Negative

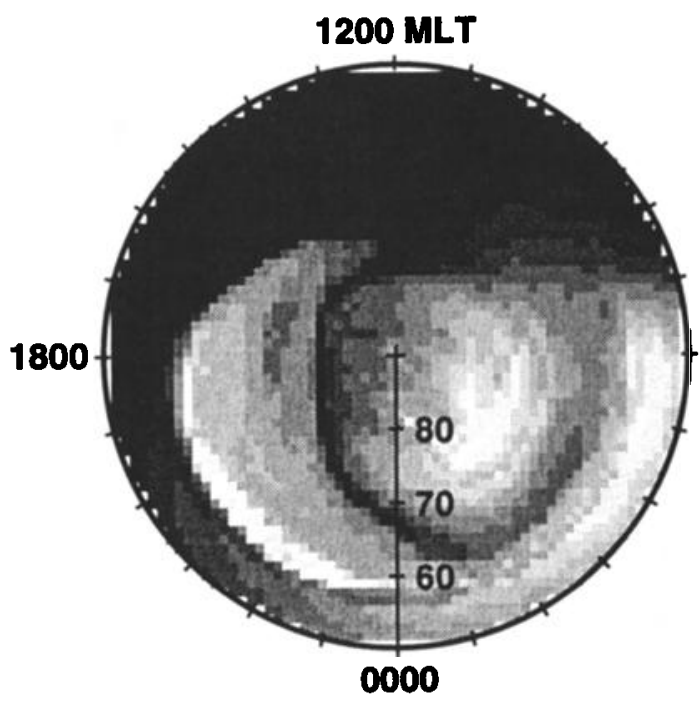

IMF B Positive

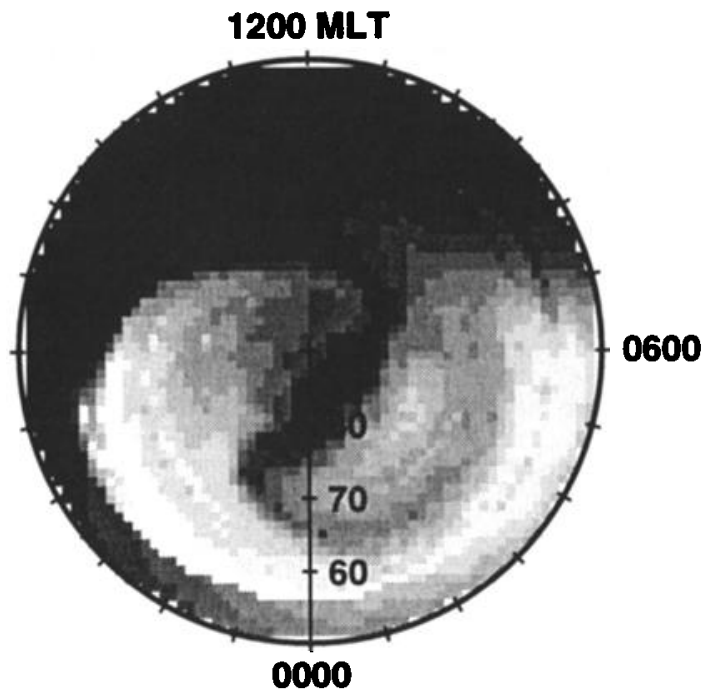

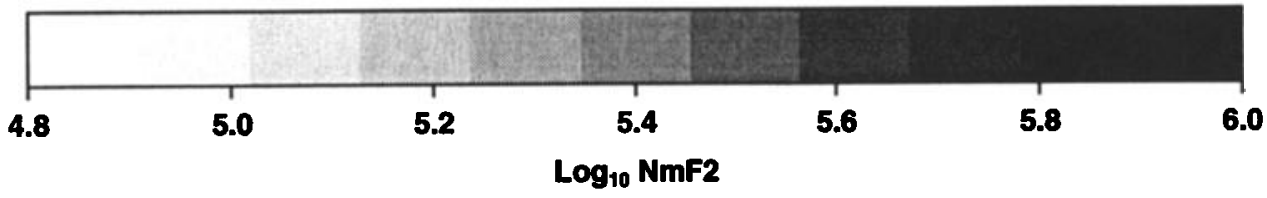

Figure 2. Snapshots of simulated $N_{m} F_{2}$ distributions at 2100 UT showing the characteristics of the tongue-of-ionization for IMF (left) $B_{v}$ negative and (right) $B_{v}$ positive conditions.

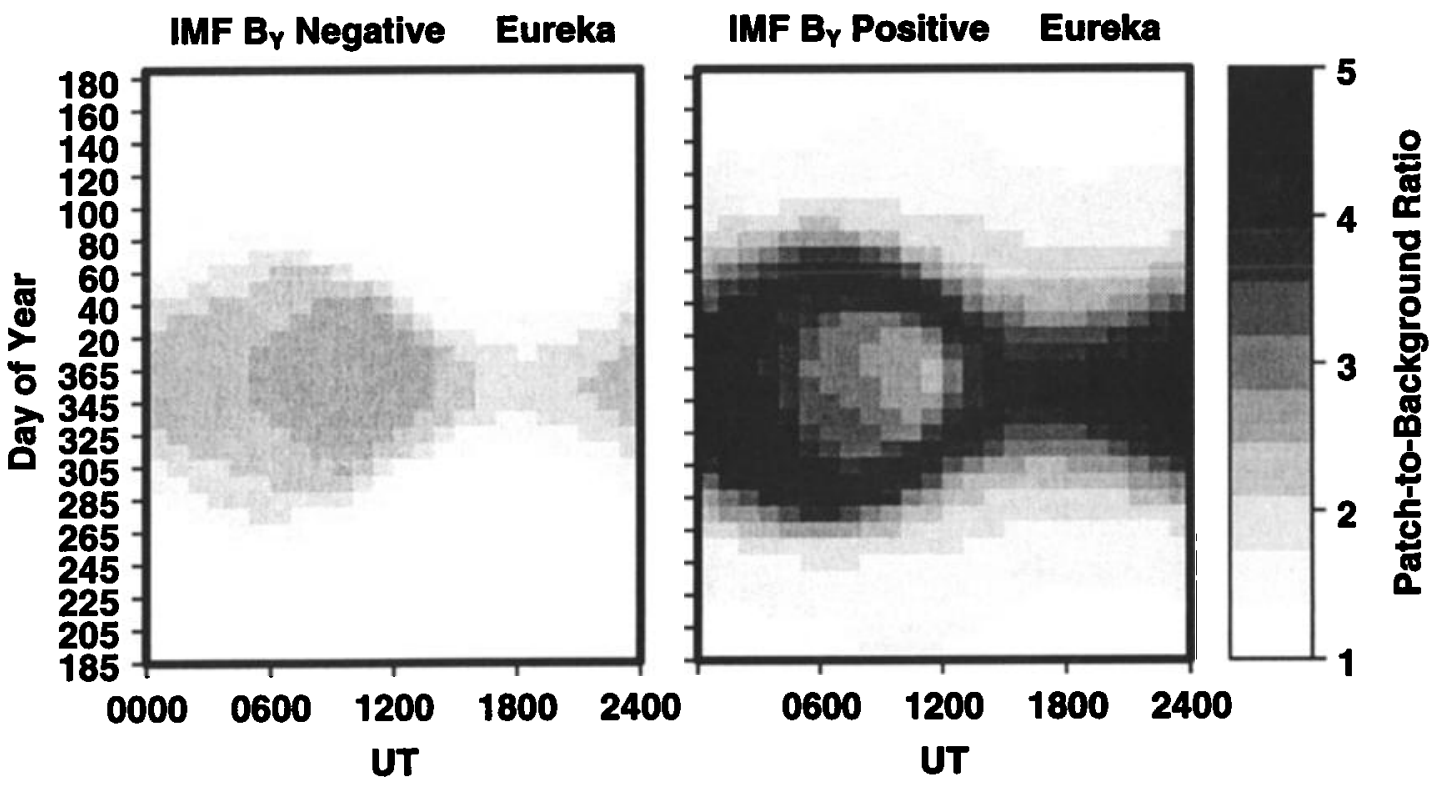

Figure 3. Eureka's local patch-to-background $N_{m} F_{2}$ ratios as a function of UT and season for IMF (left) $B_{y}$ negative and (right) $B_{y}$ positive. 

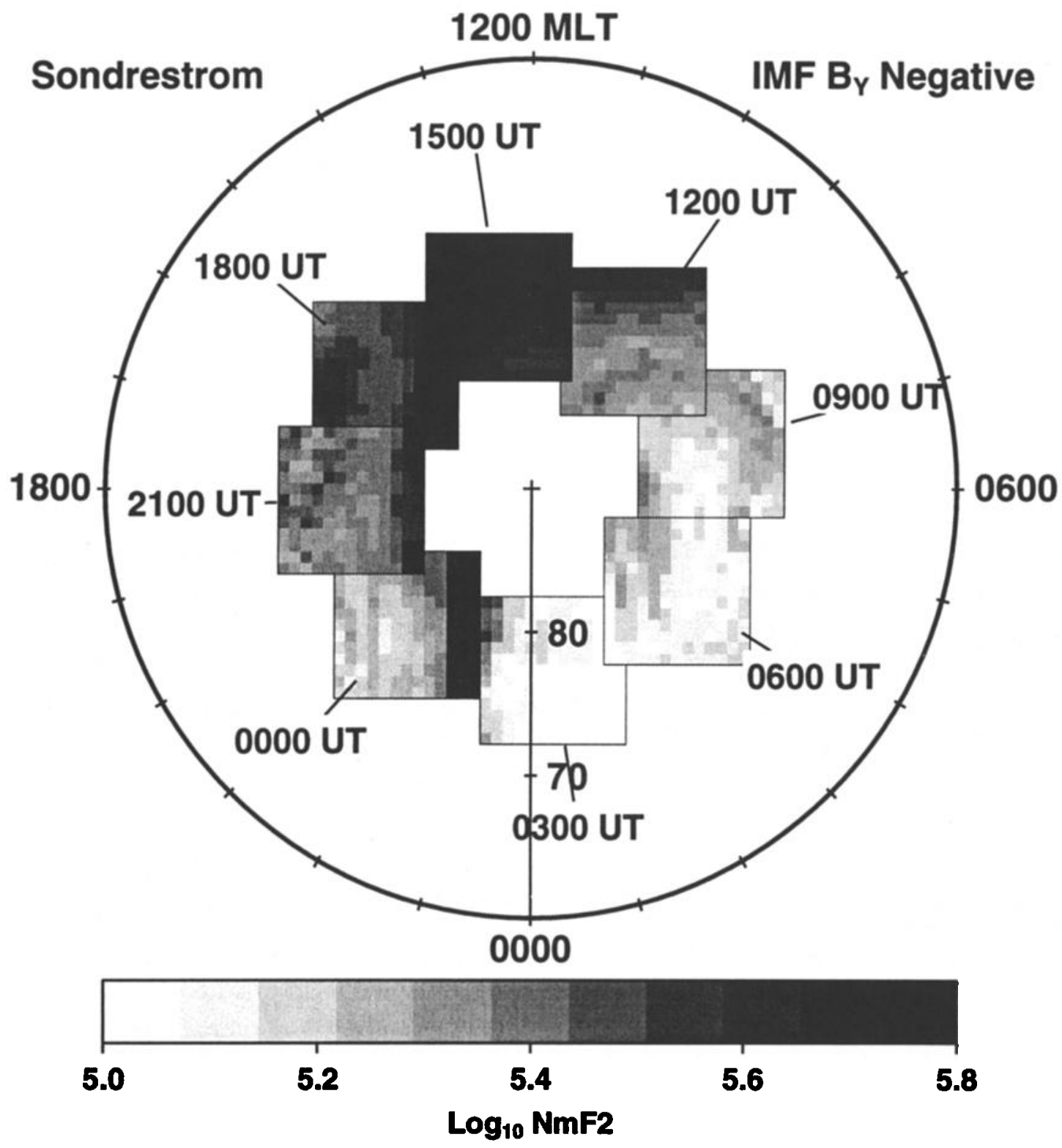

Figure 4. Eight snapshots of localized $N_{m} F_{2}$ distributions centered on Sondrestrom shown in the magnetic local time frame. Each snapshot is restricted to an approximate all-sky camera field of view. The simulation is for IMF $B_{y}$ negative conditions.

in the afternoon sector polar cap. In contrast, for $B_{y}$ positive the TOI is within the field of view. Hence patches observed from Eureka have a distinct IMF $B_{y}$ dependence.

Figure 3 shows the simulated Eureka patch-tobackground ratios for IMF $B_{y}$ negative (left panel) and $B_{y}$ positive (right panel) as a function of UT and season. As expected, the two bull's-eye patterns are very different both in intensity and morphology. For $B_{y}$ positive conditions (right panel) a bull's-eye similar to the Figure 1 prediction is obtained. The maximum patch-to-background $N_{m} F_{2}$ ratio exceeds 5. For $B_{y}$ negative this ratio barely exceeds 2 and the strongest patches are expected at solstice, diminishing toward equinox. Since, in general, $B$, varies over a wide range of values, Eureka would be expected to see a range of $N_{m} F_{2}$ ratio patterns that varies between the two shown in Figure 3. This is quite different from the prediction based 
on an ideal dawn-dusk "satellite" cut across the polar ionosphere used to generate the Figure 1 bull's-eye. In that scenario the TOI will always be crossed, hence that pattern is applicable for all $B_{y}$ cases. The restricted ground-based observer's field of view means that patch observation analyses must be carried out in conjunction with IMF $B_{y}$ information, otherwise erroneous conclusions may be drawn concerning the presence or absence of patches.

\section{Simulated Sondrestrom (Greenland) Observations}

Unlike Eureka, most other high-latitude polar cap observatories are located such that their field of view does not encompass the magnetic pole. These stations also move in local time in such a way that the field of view does not encompass the dawn-dusk slice across the polar cap. Sondrestrom is such a station, located at $67^{\circ} \mathrm{N} 309^{\circ} \mathrm{E}$ in Greenland. Assuming the same $13 \times 13$ pixel field of view centered on Sondrestrom, Figure 4 shows the $N_{m} F_{2}$ snapshot at eight equally spaced UTs during a day. These snapshots form a mosaic image of how the TOI would be observed from Sondrestrom.

Figure 4 was simulated by the TDIM using the HeppnerMaynard " $A$ " convection pattern. This pattern corresponds to southward IMF and $B_{y}$ only slightly negative. At 0000 UT, Sondrestrom is in the late evening local time sector and sees the TOI. However, for the ensuing 12 hours it is in the morning sector and does not see the TOI. Even for the IMF $B_{y}$ positive case (Figure 2, right panel) it would not see the TOI during this time interval, because the TOI is absent or weak at these UTs. Sondrestrom is at local noon at $1500 \mathrm{UT}$, a time when the polar ionosphere is most sunlit, and hence, as shown in Figure 4, there are large densities seen at this time.

Figure 5 shows the simulated UT-seasonal patch-tobackground $N_{m} F_{2}$ ratios for Sondrestrom for IMF $B_{y}$ negative (left panel) and $B_{y}$ positive (right panel) conditions. As with the Eureka predictions (Figure 3), the two patterns in Figure 5 are different, and neither is a very obvious bull's-eye pattern. The $B_{y}$ positive case (right panel) slightly resembles the bull's-eye, but the 1200 to 2300 UT period is devoid of any significantly enhanced $N_{m} F_{2}$ ratio. This is because the station is on the afternoon side while the TOI is on the morning side. For the $B_{y}$ negative case (left panel) the situation is even more complicated, with the winter solstice $N_{m} F_{2}$ ratio enhanced between 2200 UT and 0100 UT. These patterns are significantly more "noisy" than for Eureka (cf. Figures 3 and 5). This results because the Sondrestrom station moves extensively in the magnetic local time frame, and hence it samples regions of different background $N_{m} F_{2}$ (see Figure 4). In particular, it only spends a small amount of time on the dawn-dusk meridian. This is in sharp contrast to the case for Eureka (Figure 3) or the hypothetical satellite used to generate Figure 1 .

\section{Simulated NyAlesund (Svalbard) Observations}

NyAlesund is located at $79^{\circ} \mathrm{N}, 12^{\circ} \mathrm{E}$ on Svalbard Island. Its magnetic latitude (dipole), $75^{\circ}$, is almost the same as that of Sondrestrom, $77^{\circ}$. However, NyAlesund is about $70^{\circ}$ east of Sondrestrom. This longitudinal difference leads to a significant difference in the UT dependence at the two stations. Figure 6 shows the model $N_{m} F_{2}$ snapshots for
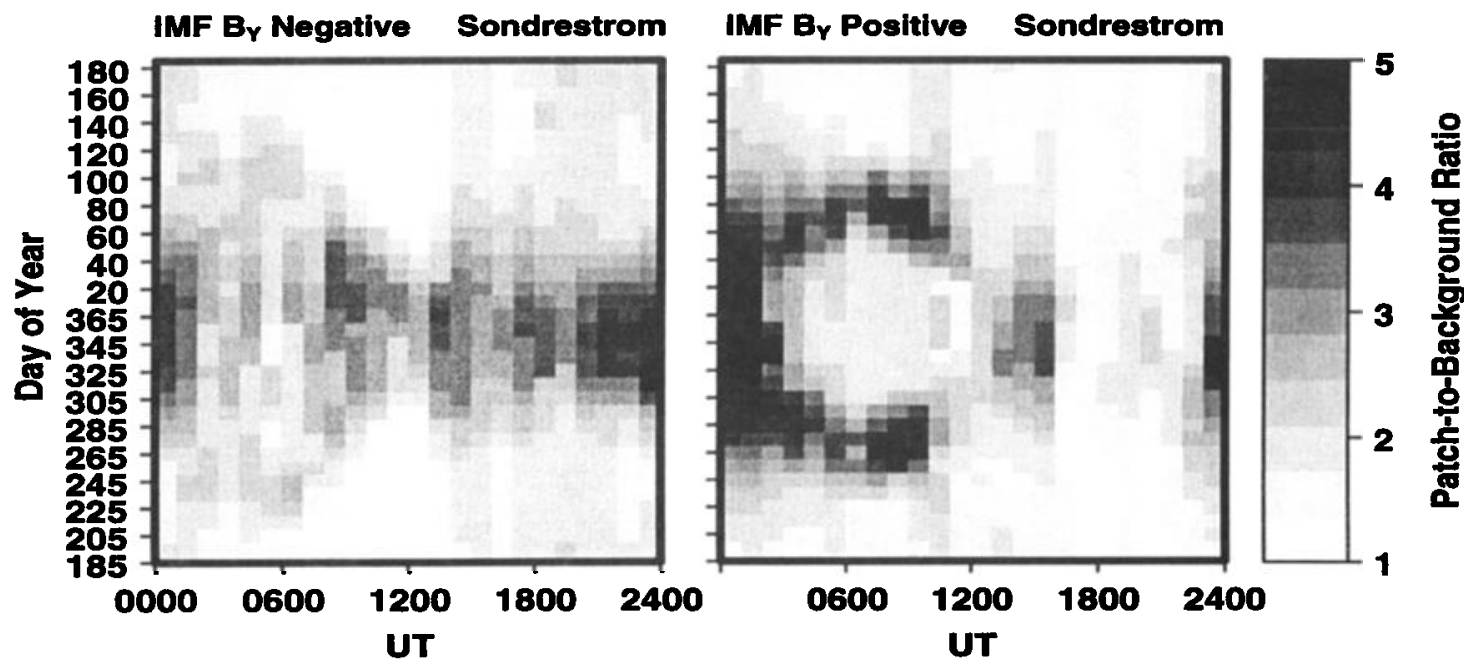

Figure 5. Sondrestrom's local patch-to-background $N_{m} F_{2}$ ratios as a function of UT and season for IMF (left) $B_{y}$ negative and (right) $B_{y}$ positive. 

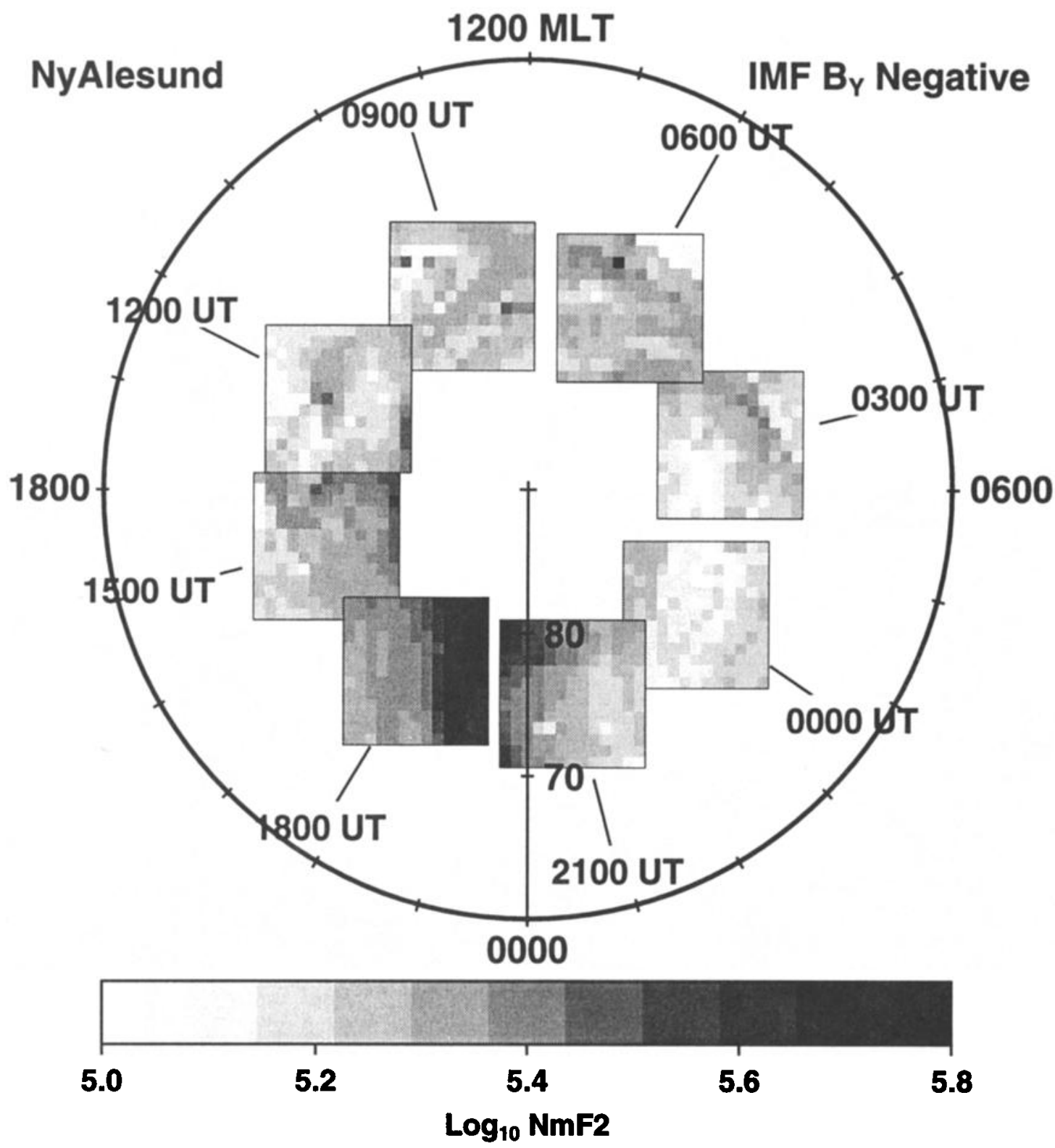

Figure 6. Eight snapshots of localized $N_{m} F_{2}$ distributions centered on NyAlesund shown in the magnetic local time frame. Each snapshot is restricted to an approximate all-sky camera field of view. The simulation is for IMF $B_{y}$ negative conditions.

NyAlesund for the identical simulation conditions used in Figure 4. At 0000 UT, NyAlesund is located in the morning sector, in contrast to Sondrestrom which was in the late evening sector. The local noon $N_{m} F_{2}$ snapshots for NyAlesund, at 0600 and 0900 UT, are devoid of enhanced plasma. This is dramatically different from Sondrestrom (Figure 4 at $1500 \mathrm{UT}$ ), where very high $N_{m} F_{2}$ values are present. These large differences between Sondrestrom and
NyAlesund are due to the UT effect, caused by the offset between the magnetic and geographic poles, which has been extensively simulated using the TDIM. Indeed, this predicted UT effect (Figures 4 and 6) has already been qualitatively presented [Sojka et al., 1993b]. In that presentation, digital ionosonde data (from $\mathrm{E}$. Weber, Phillips Laboratory) for 5 days at Sondrestrom and NyAlesund were compared with the TDIM. The 

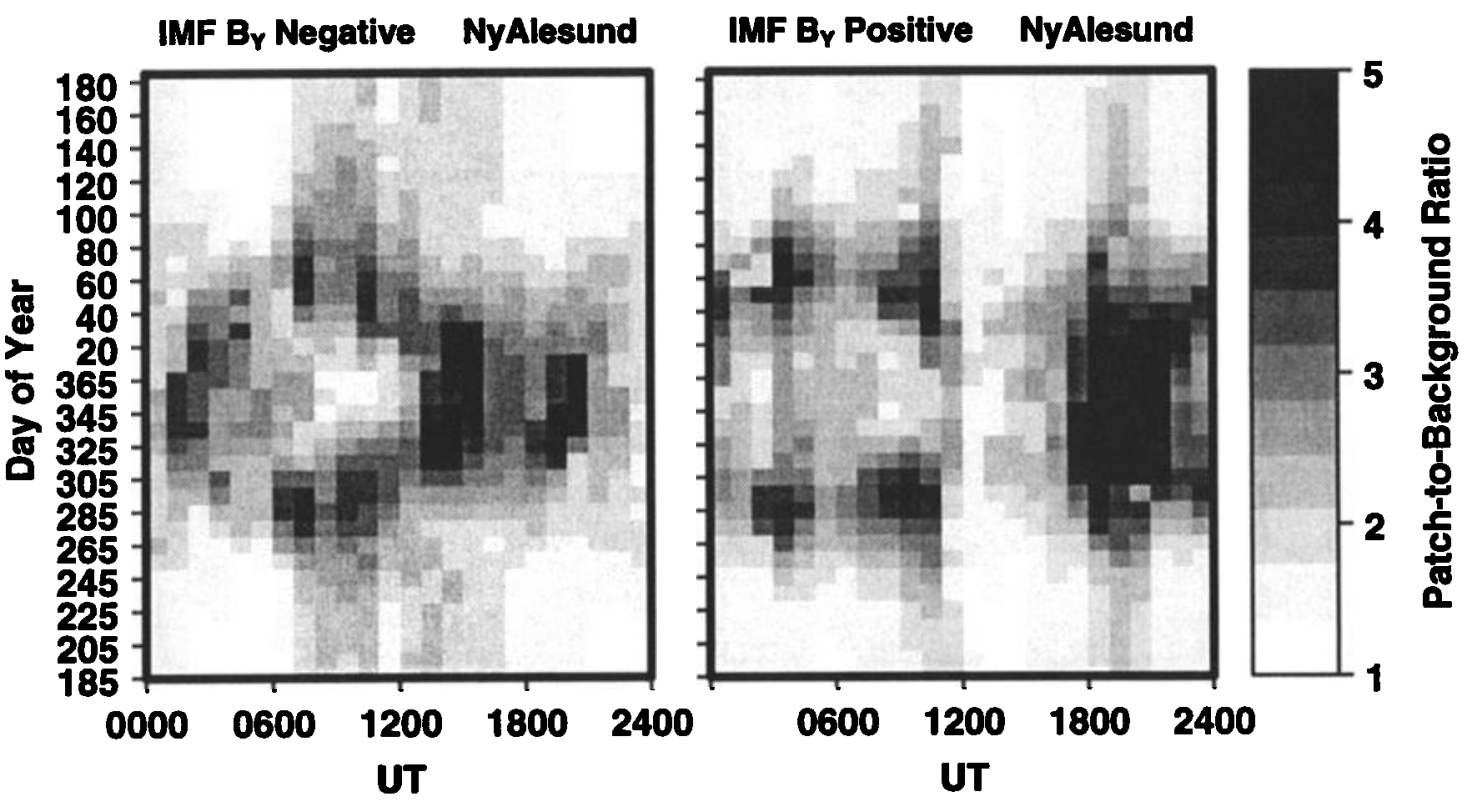

Figure 7. NyAlesund's local patch-to-background $N_{m} F_{2}$ ratios as a function of UT and season for IMF (left) $B_{y}$ negative and (right) $B_{y}$ positive.

presentation showed that the noon-midnight $N_{m} F_{2}$ values predicted in Figures 4 and 6 were observed. These observations for a more extensive period at both stations are being collected for a future patch study with $E$. Weber.

The effect of the NyAlesund UT dependence on the UTseasonal patch-to-background $N_{m} F_{2}$ ratio is shown in Figure 7. Neither IMF $B_{y}$ case shows a significant bull'seye pattern, although one could guess that both cases do show a hint of the pattern. This is somewhat different from Sondrestrom and Eureka, where neither station showed any hint of a bull's-eye pattern for IMF $B_{y}$ negative. The two NyAlesund patterns in Figure 7 are both rather noisy or variable, which is similar to that found for Sondrestrom (Figure 5) but not for Eureka (Figure 3). In the $B_{y}$ positive case (Figure 7, right panel) the pattern is broken between 1200 and 1700 UT. This is the time when the station is in the afternoon sector in a location that completely misses the $B_{y}$ positive TOI.

\section{Discussion}

The TDIM simulations of local patch-to-background $N_{m} F_{2}$ ratios for different sites (Figures 3,5, and 7) show patterns that are not as simple as the global theoretical bull's-eye of Figure 1. A particular ground-based site will be able to observe only a portion of the complete UTseasonal morphology. In addition to this, on any given day, patch observations will be sensitive to the IMF $B_{y}$ orientation. Indeed, the Eureka patch observations do not appear to show a UT dependence at winter solstice (D. McEwen, private communication, 1994); this is consistent with the model simulations shown in Figure 3 in which the morphology depends heavily on the IMF $B_{y}$ conditions. Hence extensive IMF data along with patch observations will be needed to test the predictions in Figure 3. Work has begun to carry out such a study.

The advantage of having data from multiple sites is especially clear when IMF data is lacking; if the orientation of $B_{y}$ is not known, then no prediction can be made as to which side of the polar cap is most likely to contain patches. Thus the failure of a given station to observe patches does not mean that no patches are present in the polar cap; another station at a different longitude might observe patches at that time.

Figure 8 shows the patch-to-background $N_{m} F_{2}$ ratio after combining in equal weighting the four simulated data sets: Sondrestrom $B_{y}$ negative (Figure 5, left panel), $B_{y}$ positive (Figure 5, right panel), NyAlesund $B_{y}$ negative (Figure 7, left panel), and $B_{y}$ positive (Figure 7 , right panel). This pattern is similar to the theoretical bull's-eye shown in Figure 1. In fact, by combining enough stations it is expected that the gaps still present in the Figure 8 pattern will be filled in and the Figure 1 bull's-eye will be obtained. Hence although each station sees only a small part of the UT-seasonal morphology associated with the TOI patch source, the subsets do combine to produce the whole pattern. 

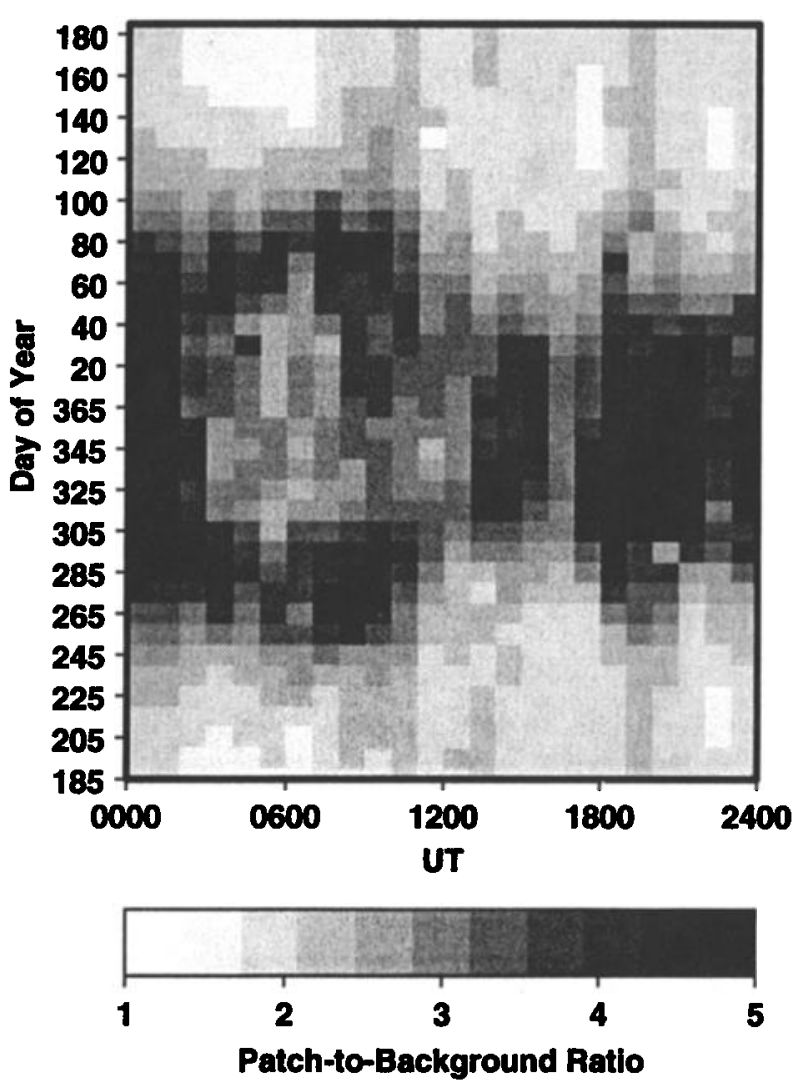

Figure 8. Patch-to-background $N_{m} F_{2}$ ratios as a function of UT and season for combined conditions of IMF $B_{y}$ positive and negative and the combined fields of view of Sondrestrom and NyAlesund.

We are currently collecting HLPS data sets both from CEDAR and from international observation campaigns to verify these predictions. Already it has been found that the intensity of polar cap scintillations correlates with the general bull's-eye pattern shown in Figure 1 [Basu et al., 1995]. In this latter study, no IMF selection was carried out. The expectation was that the scintillations are primarily associated with southward IMF conditions and that they are produced at the "trailing" edges of the polar cap patches. Hence combining all IMF data should result in a morphology that closely resembles that of the patches. This was in fact the initial finding.

\section{Conclusion}

We have attempted to cast theoretical patch predictions [Sojka et al., 1993a, 1994] in a form applicable to groundbased observational sites. We assume that the plasma source for patches is the tongue of ionization, but this study is not dependent upon any particular mechanism for fragmenting the TOI into patches. The results of this study are:

1. The global patch UT-seasonal morphology predicted by Sojka et al. [1994] is not usually observed within the restricted field of view of a single ground station.

2. Because the field of view of a single ground station does not, in general, see the TOI at all UTs, there are times when ground stations would not see patches even when they are present in the polar cap.

3. The location of the TOI is controlled by the IMF $B_{v}$, and hence it can move into and out of the field of view of a single ground observer as $B_{y}$ varies.

4. The theoretical bull's-eye of patch occurrence can be reconstructed from patch observations at multiple sites, and if an adequate longitudinal distribution of sites is available, the resulting bull's-eye pattern will be independent of the IMF $B_{y}$ component.

Ideally, one would desire data from several stations well dispersed in longitude; however, it can be seen from Figure 8 that the inclusion of (simulated) data from just two stations, separated by only about $70 \mathrm{deg}$ of longitude, already recovers a significant amount of detail from the total UT-seasonal morphology that was displayed in Figure 1.

This study has laid the framework for observation-model comparisons of plasma patches. In the absence of IMF data it will be difficult to make one-to-one observation-model comparisons because of the strong IMF $B_{y}$ control of the polar ionosphere (i.e., see Figure 3 for Eureka).

Acknowledgments. This research was supported by NASA grant NAG5-1484 and NSF grants ATM-93-02165 and ATM-93-08163 to Utah State University.

\section{References}

Anderson, D. N., J. Buchau, and R. A. Heelis, Origin of density enhancements in the winter polar cap ionosphere, Radio Sci., 23, 513-519, 1988.

Basu, S., S. Basu, J. J. Sojka, R. W. Schunk, and E. MacKenzie, Macroscale modeling and mesoscale observations of plasma density structures in the polar cap, Geophys. Res. Lett., 22, 881-884, 1995.

Bowline, M., J. J. Sojka, and R. W. Schunk, UT control of $\mathrm{N}_{e}$ patches in the polar ionosphere (abstract), Eos Trans. $A G U$, 73(43), Fall Meet. Suppl., 416, 1992.

Bowline, M., J. J. Sojka, and R. W. Schunk, Patches in the polar ionosphere: Plasma source variability, Eos Trans. AGU, 74(43), Fall Meet. Suppl., 463, 1993.

Buchau, J., B. W. Reinisch, E. J. Weber, and J. G. Moore, Structure and dynamics of the winter polar cap $F$ region, Radio Sci., 18, 995-1010, 1983.

Buchau, J., E. J. Weber, D. N. Anderson, H. C. Carlson Jr., J. G. Moore, B. W. Reinisch, and R. C. Livingston, 
Ionospheric structures in the polar cap: Their origin and relation to $250-\mathrm{MHz}$ scintillation, Radio Sci., 20, 325338, 1985.

Decker, D. T., C. E. Valladares, R. Sheehan, S. Basu, D. N. Anderson, and R. Heelis, Modeling daytime $F$ layer patches over Sondrestrom, Radio Sci., 29, 249-268, 1994.

de la Beaujardiere, O., V. B. Wickwar, G. Caudal, J. M. Holt, D. J. Craven, L. A. Frank, L. H. Brace, D. S. Evans, J. D. Winningham, and R. A. Heelis, Universal time dependence of nighttime $F$ region densities at high latitudes, J. Geophys. Res., 90, 4319-4332, 1985.

Foster, J. C., and J. R. Doupnik, Plasma convection in the vicinity of the dayside cleft, J. Geophys. Res., 89 , 9107-9113, 1984.

Hardy, D. A., M. S. Gussenhoven, R. Raistrick, and W. J. McNeil, Statistical and functional representations of the pattern of auroral energy flux, number flux, and conductivity, J. Geophys. Res., 92, 12,275-12,294, 1987.

Hedin, A. E., MSIS-86 thermospheric model, J. Geophys. Res., 92, 4649-4662, 1987.

Heppner, J. P., and N. C. Maynard, Empirical high-latitude electric field models, J. Geophys. Res., 92, 4467-4489, 1987.

Lockwood, M., and H. C. Carlson Jr., The production of polar cap electron density patches by transient magnetopause reconnection, Geophys. Res. Lett., 19, 1731-1734, 1992.

Rodger, A. S., M. Pinnock, J. R. Dudney, K. B. Baker, and R. A. Greenwald, A new mechanism for polar patch formation, J. Geophys. Res., 99, 6425-6436, 1994.

Sato, T., Morphology of ionospheric F2 disturbances in the polar regions, Rep. lonos. Space Res. Jpn., 13, 9195, 1959.

Schunk, R. W., A mathematical model of the middle and high latitude ionosphere, Pure Appl. Geophys., 127, 255-303, 1988.

Schunk, R. W., and W. J. Raitt, Atomic nitrogen and oxygen ions in the daytime high-latitude $F$ region, $J$. Geophys. Res., 85, 1255-1272, 1980.

Schunk, R. W., and J. J. Sojka, Ion temperature variations in the daytime high-latitude $F$ region, J. Geophys. Res., 87, 5169-5183, 1982.

Schunk, R. W., and J. C. G. Walker, Theoretical ion densities in the lower ionosphere, Planet. Space Sci., $21,1875-1896,1973$.

Schunk, R. W., W. J. Raitt, and P. M. Banks, Effect of electric fields on the daytime high-latitude $E$ and $F$ regions, J. Geophys. Res., 80, 3121-3130, 1975.

Schunk, R. W., P. M. Banks, and W. J. Raitt, Effect of electric fields and other processes upon the nighttime high-latitude $F$ layer, J. Geophys. Res., 81, 3271-3282, 1976.

Schunk, R. W., J. J. Sojka, and M. D. Bowline, Theoretical study of the electron temperature in the high-latitude ionosphere for solar maximum and winter conditions, $J$. Geophys. Res., 91, 12,041-12,054, 1986.

Sojka, J. J., Global scale, physical models of the $F$ region ionosphere, Rev. Geophys., 27, 371-403, 1989.

Sojka, J. J., and R. W. Schunk, Predicted diurnal variations of electron density for three high-latitude incoherent scatter radars, Geophys. Res. Lett., 9, 143-146, 1982.

Sojka, J. J., W. J. Raitt, and R. W. Schunk, A theoretical study of the high-latitude winter $F$ region at solar minimum for low magnetic activity, J. Geophys. Res., $86,609-621,1981 \mathrm{a}$.

Sojka, J. J., W. J. Raitt, and R. W. Schunk, Theoretical predictions for ion composition in the high-latitude winter $F$ region for solar minimum and low magnetic activity, J. Geophys. Res., 86, 2206-2216, 1981 b.

Sojka, J. J., M. Bowline, and R. W. Schunk, Simulation of $\mathrm{N}_{e}$ patches in the polar ionosphere, Eos Trans. $A G U$, 73(43), Fall Meet. Suppl., 414, 1992.

Sojka, J. J., M. D. Bowline, R. W. Schunk, D. T. Decker, C. E. Valladares, R. Sheehan, D. N. Anderson, and R. A. Heelis, Modeling polar cap $F$ region patches using timevarying convection, Geophys. Res. Lett., 20, 17831786, 1993a.

Sojka, J. J., R. W. Schunk, M. D. Bowline, and E. J. Weber, Model-observation comparisons that show the polar cap patch UT dependence in winter, Eos Trans. $A G U$, Fall Meet. Suppl., 74, 94, $1993 \mathrm{~b}$.

Sojka, J. J., M. D. Bowline, and R. W. Schunk, Patches in the polar ionosphere: UT and seasonal dependence, $J$. Geophys. Res., 99, 14,959-14,970, 1994.

Tsunoda, R. T., High-latitude $F$ region irregularities: A review and synthesis, Rev. Geophys., 26, 719-760, 1988.

Valladares, C. E., S. Basu, J. Buchau, and E. FriisChristensen, Experimental evidence for the formation and entry of patches into the polar cap, Radio Sci., 29, 167-194, 1994.

Weber, E. J., J. Buchau, J. G. Moore, J. R. Sharber, R. C. Livingston, J. D. Winningham, and B. W. Reinisch, $F$ layer ionization patches in the polar cap, $J$. Geophys. Res., 89, 1683-1694, 1984.

Weber, E. J., J. A. Klobuchar, J. Buchau, H. C. Carlson Jr., R. C. Livingston, $O$. de la Beaujardiere, M. McCreday, J. G. Moore, and G. J. Bishop, Polar cap $F$ layer patches: Structure and dynamics, J. Geophys. Res., 91, 12,121$12,129,1986$.

M. D. Bowline, R. W. Schunk, and J. J. Sojka, Center for Atmospheric and Space Sciences, Utah State University, Logan, UT 84322-4405. (e-mail: usera@theor3.cass.usu.edu; schunk@cc.usu.edu; fasojka@ sojka.cass.usu.edu)

(Received July 10, 1995; revised November 7, 1995; accepted January 23, 1996.) 